\title{
Creating a reflective space in higher education
}

The case of a Swedish course for professional principals

\author{
Katina Thelin
}

\begin{abstract}
This article considers the conditions, possibilities, and challenges of creating what is referred to here as a 'reflective space' within a higher education course for principals. It is informed by the findings of a qualitative research inquiry conducted in the interests of enhancing the principals' learning and professional praxis and the university educators' pedagogical praxis, within a Swedish course for school and preschool principals. Analysis of the findings highlighted two significant patterns. The first relates to the transformative benefits of creating a 'reflective space' for the principals attending the course. The second is more ambiguous and reflects their relation to and engagement with scientifically constructed knowledge. Based on these findings, the article offers considerations relevant for creating 'reflective spaces' as a means to enhance the quality of learning in higher education. Additionally, some guiding pedagogical implications are included in the final remarks.
\end{abstract}

\section{KEYWORDS}

leadership, leading, principal training, practice, practice architectures, reflection, reflective space

The importance of reflection is widely recognised in literature on professional praxis, where it is often associated with lifelong, or continuing, professional learning and practice improvement (e.g. Boud et al. 1985, 2006; Dewey 1933; Kolb 1984; Schön 1983). Definitions and descriptions of reflection vary among researchers within the field, although most view reflection as a means to learn from and develop practice. Reflection is also closely related to problem-solving (Schön 1983), empowerment and emancipation (Freire 1972). In addition, it is often seen as a means to bridge an alleged 
'gap' between theory and practice (e.g. Mihailova 2014; Zuber-Skerritt 1997), or between 'the "roles" of theorist and practitioner' (Kemmis 2009: 468). Moreover, reflection is sometimes viewed as a pedagogical strategy used to enhance learners' ability to use, develop and integrate different types of knowledge (e.g. experience-based knowledge and scientifically constructed knowledge).

In the context of higher education, and from a pedagogical praxis perspective, this recognition of the importance of reflection has created a need to develop reflective learning environments for aspiring or practising professionals. From the perspective of university educators, this means providing opportunities and making arrangements to support practices in which participants are asked to reconceptualise and problematise 'the familiar in their own practices', to look for 'the "unasked" questions', and to 'renovate' 'existing patterns of thought and practice by exposing the underlying ideology, and to submit them to a rigorous critique so that oppressive processes can be challenged, and alternatives established' (Holmes 2002: 77). Inviting course participants to engage in such practices is, in this article, seen as one way to nurture praxis in higher education.

Inspired by research on professional self-study (Darling-Hammond 2006; Loughran et al. 2004; Russell and Loughran 2010) and the theory of practice architectures (Kemmis et al 2014), a group of university educators, of whom the author is one, endeavoured to create what is here referred to as a 'reflective space' for principals in education. This article explores some conditions, possibilities and challenges of this endeavour. It is informed by the findings of a qualitative research inquiry conducted in the interests of reviewing and developing a course within the Swedish National School Leadership Training Programme (Rektorsprogrammet). Analysis of the findings highlighted two notable patterns. The first relates to the transformative benefits of structured reflections for course participants. The second is more ambiguous, reflecting participants' relation to and engagement with scientifically constructed knowledge encountered in course literature and in lectures.

The purpose of this article is to unpack and comment on these patterns and their relevance for the professional praxis of the participating principals and the pedagogical praxis of the university educators. Using the theory of practice architectures as a lens, it offers some considerations on what enabled and constrained participants' learning in the course. Thus, it contributes to the ongoing discussions about reflection and conditions for praxis in higher education. It might also be instructive for those who want to enact 
reflective practice and critical reflection in higher education. The article is structured as follows: after a short description of the particular course and context, the theoretical perspectives are outlined. Then the research inquiry (data, methods, and limitations) are presented, followed by a section in which the findings relevant for this article are presented and discussed. The article ends with a conclusion based on the findings and considerations of their pedagogical implications.

\section{The course and context}

In Sweden, the National School Leadership Training Programme is a stateregulated professional education programme for school and preschool principals. It is also an academic, advanced-level programme, constructed as commissioned education. As such, it is offered at six Swedish universities. The programme is compulsory for newly appointed principals and is completed over the course of three years. It comprises a total of thirty higher education credits at second-cycle level and consists of three courses: School legislation and exercising public authority, Management by goals and objectives, and School leadership (Skolverket 2015). The inquiry drawn upon in this article was conducted in the latter of this suite of three courses. At the university where this inquiry was conducted, the interpretation of the overall purpose of the programme (encompassing the three courses) is to enhance principals' learning and leading practices.

\section{Theoretical framework}

\section{Practice and practice architectures}

The work presented below is based on the definition of practice as 'a form of socially established cooperative activity involving characteristic forms of understanding (sayings), modes of action (doings), and ways in which people relate to one another and the world (relatings) that hang together in a distinctive project' (Rönnerman and Kemmis 2016: 95). According to this theory, practice is enabled and constrained by cultural-discursive, material-economic and social-political arrangements. Together, these arrangements form the 'practice architectures' that make possible, or hold in place, practices (e.g. leadership, learning and reflection) (Kemmis et al. 2014). 


\section{Learning and change}

Drawing on this theory, (professional) learning is here viewed as a practice 'composed of sayings, doings and relatings that hang together' (Kemmis et al. 2014: 33) in a distinctive way, and thus enabled and constrained by various cultural-discursive, material-economic, and social-political arrangements. In this article, reflection, or reflecting practice, is treated as part of professional learning practice. Moreover, since (professional) learning aims to change other practices (for instance, principals' leading practices), it is also viewed as a practice-changing practice (Kemmis 2009). As such, it 'transforms the sayings, doings and relating that compose those other practices' (Kemmis 2009: 463). This feature of learning is important for the purpose of this article, as it links educational activities to participants' professional practices.

Furthermore, with respect to participants' learning and leading practices, we can distinguish between first and second-order change. The difference between first and second-order change (Argyris and Schön 1978; Ellström 2006) has been defined in different ways by different scholars. Since educators tend to rely on various definitions, we have not found it fruitful to select only one. Instead, an integrated conceptual framework (Levy 1986), based on definitions provided by scholars from different fields, has served as a source of inspiration for analysing the data collected in this project. According to this framework, first-order change is characterised as: change in one or a few dimensions, components, or aspects; quantitative; and content-related. Second-order change, however, is multidimensional, multicomponent, or multifaceted; qualitative; and contextual. Moreover, first-order change is incremental and does not alter the world view or state of being, whereas second-order change is innovative ('revolutionary') and results in new ways of viewing the world or state of being (Levy 1986: 11).

\section{The notion of space}

With respect to reflective space, the notion of space is given a specific meaning. Space is described by Stephen Kemmis et al. (2014) in terms of three dimensions: the semantic, the physical and the social. The semantic space is where a common discourse, language and meaning is shared discursively and mutual understandings are constructed through 'sayings'. The physical space is where 'shared locations in space and time enable interactions through shared activities, resources and work, which are en- 
countered within particular physical set-ups and realised in doings'. Finally, the social space is where 'shared encounters afford different ways of relating to one another to produce particular kinds of social relationships, agency and power, realised through relatings' (Rönnerman et al. 2015: 69). Based on these notions, a 'reflective space' can be understood as a space constituted by socially established arrangements that enable and hold reflecting practices in place. In this sense, creating a 'reflective space' means creating arrangements to support such practices.

\section{Creating a reflective space}

As previously mentioned, the theory of practice architectures served as an important resource for the creation of a reflective space. With respect to the semantic dimension of this space, the theory of practice architectures was introduced and presented as a theoretical and analytical resource, providing participants with semantic tools for understanding and communicating practice. With respect to the physical dimension of this space, the participants were provided with a structure, referred to as a reflection protocol, that was intended to help them observe, document, and reflect upon their leading practice. A digital version of this protocol was published on the digital learning platform used within the programme, together with instructions on how to use it. Assignments, based on participants periodically selecting, documenting and reflecting on situations in their own professional praxis, were constructed and described in a study guide that was also published on the platform. To support the intended activities, participants were divided into groups of five to eight. Time for group activities related to participants' documentation and reflection was allocated and scheduled. Furthermore, during the course's residential seminars, each group was offered a small conference room for collaborative work. In the social dimension, documentation and reflection activities served several purposes. First and foremost, these activities aimed to help participants distance themselves from their own practice, forcing them to take a step back and reflect on the practice as it appeared to them in their structured documentation. From this position, participants were encouraged to alter their perspective on their current practice by using concepts, models and theories encountered in the course literature, as well as the experiences of other participants in the programme. Altogether these arrangements, set up to facilitate participants' individual and collective reflection, defined the reflective space created for participants in the course. 


\section{The research inquiry}

The aim of the inquiry was to explore how the course participants perceived the reflective practice as enabling or constraining their learning, and how it affected their leading practice. The key guiding question was: How do principal leading practices, and praxis, change on the basis of participants periodically selecting, documenting and reflecting upon their leading practices? Data in this inquiry was collected from a group of seventy course participants. Out of this group, sixty-three agreed to have their work analysed as part of the inquiry. ${ }^{1}$ Since each participant handed in three documents based on their work with the reflection protocol and a final report based on these documents, the overall material consisted of 189 pieces of documentation and reflection and sixty-three final reports.

Qualitative document content analysis was used to analyse the data. Analysis was carried out in three steps, guided by the following questions: 1) What expressions of change appear in the data? 2) What is the nature of any change that appears in the data? 3) What patterns of change appear in the overall material (on a group level)?

The first step was to carefully read all the documents, in order to find expressions of change in any aspect of the documented practice and/or the arrangements holding it in place. When detected, these changes were coded using concepts drawn from the theory of practice architectures. The next step was to distinguish between first and second-order changes, and the third and last step was to look for patterns in the overall material.

Moving on to the analysis and discussion of the main findings, it is important to bear in mind that the study carried out and referred to in this article does not provide knowledge about practice as such. Since we (the university educators) did not make any observations ourselves, but had to rely on participants' reporting, we cannot be sure that the changes described in this article are actually found in the sites where participants' leading practices are formed. What in their reporting appears to be changes in the physical time-space, may or may not correspond to changes that have been, or will be, realised by the participants in the medium of activity or work. Additionally, what appears to be changes in the social space may or may not correspond to changes that have been, or will be, realised by the participants in the medium of power and solidarity. Clearly this limitation of the inquiry must be taken into account when considering the findings and their implications. Yet, there is reason to believe that something happened to participants' prac- 
tice as a result of their engagement in these educational activities, and that this is somehow captured in their writings, just as there is reason to believe that the reported changes, even if limited to participants' general understandings of leadership, created new or revised conditions for their own practice as well as other related practices.

\section{Expressions of change in participants' reporting}

Due to the way the reflection protocol was constructed, participants' attention was directed towards the various elements that, according to the theory of practice architectures, constitute a practice. This targeted attention seemed to give rise to important discoveries and new insights relevant to them as leaders, as indicated in the following example: 'I have seen that I use my language, both verbally and physically, to a great extent to reinforce what I want to do'. In participants' writing (within the structure of the protocol and in the final reports), observations like this were often reported together with the phrase, 'I have become aware of ...', or 'I have become more aware of ...'.

In some cases, this increased awareness was revealed when several documents were placed next to each other, for instance highlighting that participants' ways of relating to staff were not reflecting their intentions, or that the documented doings were not in accordance with the documented sayings. The discovery of such variations and inconsistencies within practice seems to have stimulated some of the participants' reflection on the arrangements, as illustrated below:

... by looking more closely at the arrangements, I have seen that there is a historical picture of difficulties of cooperation and uneven power hierarchy ... . It has also become visible how ... unspoken cultures and norms may be expressed in staff absence and scheduling ....

The importance of bringing arrangements into the reflection as a means to better understand practice was often stressed in participants' meta-reflections:

In the analysis of the data I have available, I have realised how important it is to reflect on the arrangements and their significance. ... I haven't thought so much about that before. ... I find that the more I lift my head and practice 'zooming out' in order to create an understanding of the preschool's background, assignments and conditions, the more I understand why, for example, some discussions arise. 
In the final reports, participants described how this structured reflection affected their leading practice. When analysing these documents, expressions of change were found in all dimensions of practice. Some of the changes were limited to a single specific situation, selected, documented and reflected upon, whereas others were more comprehensive. The nature of the changes identified was found to differ in ways corresponding to first and second-order change variations (see above; Levy 1986).

An example categorised as a second-order change will be presented here. The report from which the example was drawn begins with a participant, who is a preschool principal, stating that her professional self-image changed throughout the course:

At the beginning of the course I was convinced that I was a democratic leader. Today I read my work and find that I had not understood the meaning of democratic leadership and that I had misunderstood the leader's role. ...

Later in the report this is framed as a conceptual issue: 'I mixed together the concepts "democratic" and "kind".

According to this participant, her journey towards a new practice began when she started to examine some of the ideas on which she based her leadership: 'For me, the problem was that I misinterpreted the notion of [democratic] relation'. She continued to develop her understanding and explained how involvement in the work transformed her leadership, one step at a time:

The development of my leading practice is reflected in what was written in the reflection protocols, from the first to the last. I started to see and consider staff as co-actors, co-creators of visions and processes. I tried to create a deeper understanding of the goal by discussing and interpreting it at different levels. I understood that delegation of tasks has nothing to do with democracy.

However, according to this participant, the change described would not have occurred without the theoretical input she received throughout the course.

The documentation of my leading practice in the reflection protocols contains many thoughts about staff satisfaction. But there is nothing about their understanding, commitment, and participation in the process of change. With the help of the course content, I discovered that I was not the democratic leader I thought. 
For this participant, as for many others, literature became an important source from which definitions, concepts and theoretical reasoning, as well as images of practices similar to or different from their own, were borrowed.

The influence of literature is reflected in the frequent use of certain field-specific concepts (e.g. authoritarian, democratic, sensemaking, and distributed), and metaphors (e.g. a gardener, a navigator, or a conductor) in participants' writing. In the final reports such concepts and metaphors were used by the participants when describing how their practices had changed as a result of reflection, typically in writings where the participant compared their former practice to the new emerging practice. When changes were alluded to or described in participants' final reports, they were similar to each other, and to a large extent reflected common perspectives and dominant institutionalised knowledge on leadership. This indicates not only the course participants' openness to questioning their own practice, but also a specific way of relating to scientifically constructed knowledge, which from this point in the article will be referred to as a self-regulatory and self-correcting stance.

In summary, expressions of change were found in all dimensions of participants' practice. In the next section three different kinds of closely related change are presented. These were alluded to by many of the course participants and are therefore considered relevant for the broader discussion of praxis in higher education.

\section{Changing praxis}

Participants' reporting displayed some common features relevant to change within leading praxis. These are described here in terms of a move from an essentially instructive leadership towards a more communicative leadership; from an essentially individual leadership practice towards a more collective one; and from an essentially reactive leading practice towards a more reflective one.

The move from an essentially instructive towards a more communicative leading practice became evident in writings where participants contrasted previously held views on leadership with emerging ones. In the former, leadership was about conveying to others what needs to be done, and perhaps also how the work ought to be done; to 'instruct', 'drive through' and 'drive forward'. Whereas in the new, emerging leadership, communication with staff was given greater importance. Some of the participants also used contrasting concepts or word pairs such as 'manager-leader', 'top down-bottom up' and 
'authoritarian-democratic' to communicate this change. In their reporting, this type of change was often motivated by reference to the staff's skills and opportunities to grow in their respective occupational roles, and sometimes illustrated by use of metaphors. In addition, the importance of communication and the prominence of dialogue were often stressed. In participants' descriptions of the emerging views on leadership, creating space and venues for meetings and conversations were activities frequently mentioned, as were listening and asking questions rather than giving answers. In summary, this move from an essentially instructive towards a more communicative leading practice involved reducing unilaterally directed information in favour of mutual dialogue and listening. It was about a transition from rational and instrumental to communicative action, according to which it follows that leadership becomes less instructive and prescriptive and instead more sensemaking in nature. As such, it is closely related to the second type of change: from an essentially individual towards a more collective leading practice.

The description of this second type of change originates from writings in which participants describe the emergent leading practice as a social activity. In the reporting, this aspect of the emergent leadership practice was often described and illustrated with the help of metaphors. Several, for example, compared principals' leadership to that carried out by a conductor or a director before a concert or on a theatre set. These descriptions of the emerging leadership practice can be seen as a further development of those previously reported on the basis of the concept of directing (or giving direction), but with a clearer emphasis on the group rather than the individual. In the participants' writings, these were interspersed with concepts such as 'collective' or 'distributed leadership'. Moreover, this change was often associated with shared responsibility and referred to as a means to reduce the weight on principals' shoulders. The move from an essentially individual towards a more collective leading practice has significance for principals' ways of relating to their employees. In the participants' reports, this aspect of change was recurrently expressed in writings containing terms such as 'we', 'together' and 'joint'.

The third type of change, from an essentially reactive towards a more reflective leading practice, is as the label suggests strongly associated with reflection as a prerequisite for qualified professional acting. In participants' reporting, this aspect of the emerging leadership practice was defined in contrast to a former practice in which principals' fast response and ability to act were highly valued. When describing the emerging leadership practice, 
the advantage of 'taking a step back' and 'letting things take time' was often emphasised. Moreover, the importance of setting aside time and using structures that facilitate reflection (individually and collectively) was often stressed. The prominence of reflection in the descriptions of the emerging leadership practice was justified by references to participants' own experience of reflection as part of their working with the self-studies.

This comprehensive description of three closely related moves relevant to participants' leading practices which emerged from our search for patterns in the overall data is relevant to the wider discussion on higher education and its impact on praxis. First, these changes indicate that participants' learning within the 'reflective space' has contributed to a more democratic praxis, since from an employee's perspective, the changes described imply increased opportunities for participation and influence. Second, they suggest that principals are responsive to scientifically constructed knowledge, and that professional education has an impact on their leading practices. However, from a pedagogical perspective, there are other implications that warrant further consideration.

\section{Pedagogical implications}

As shown above, most participants described changes to their leading practice, or indicated a desire to change their practice, based on their critical reflections on their own professional practices during the course. Additionally, many demonstrated a will to let course material, including literature and lectures, influence their daily work. In this regard the findings correspond to the national Goal Document (Skolverket 2015) according to which participants are expected to 'develop the ability to critically review their own practice' and on the basis of this activity 'formulate strategies for development and change' (Skolverket 2015: 2). From the perspective of university educators such findings are encouraging (and somewhat rewarding).

Yet at the same time, and partly for the same reasons, they come across as slightly disturbing, since they might also be indicating that professional practice is not really treated as a legitimate source of knowledge, that local needs and conditions are not given appropriate significance, and that participants see themselves as consumers rather than producers of the knowledge they need to further their practice. Moreover, tendencies to act in a way that might be considered rule-following, as a result of participants' self-regulatory and self-corrective stances, are potentially closing down opportunities to be 
critically reflective with respect to scientifically constructed knowledge, as well as creative and innovative. When literature becomes the reference point directing the change towards certain ways of understanding, saying, doing and relating, reflection runs the risk of becoming an act of alignment, rather than an open-ended 'dialectic process' (Mihailova 2014) in which theory 'is used to inform practice and vice versa' (Mihailova 2014: 31, with reference to Roth 1989: 34-35). This is problematic considering that the programme is not merely a form of professional education, but also an academic advancedlevel education, in which participants are expected to develop their ability to critically reflect on and problematise already existing scientifically constructed knowledge, to integrate and make autonomous use of knowledge, and to produce knowledge in a scientifically reliable way (Higher Education Ordinance 1993; Swedish Higher Education Act 1992). In this regard, the 'reflective space' created to enhance participants' learning and leading practices was somehow limited, or perhaps limiting, in ways that were not intended.

These particular findings have, since the inquiry, prompted us (the university educators) to reflect on what might have been enabling or constraining the participants' reflection during the course (that is, making certain kinds of critical reflection and change possible, but not others) and how this practice can be developed as a means to nurture praxis in higher education. In the next section, some arrangements considered relevant to this discussion are presented.

\section{Enabling and constraining arrangements}

Among many arrangements affecting participants' reflective practice, and indirectly their professional practices, are those previously described as part of our creating of a 'reflective space'. Examples include the use of the theory of practice architectures; the structure (reflection protocols) and related instructions; the assignments and the course literature; and the time allocation. Out of these, the structure (i.e. reflection protocols) appears to be one of the more influential. The following quote from one participant's writing provides an example of its perceived significance:

Looking at my leading practice with the help of sayings, doings, relatings helps me understand how complex the reality is. We have learned a good method to get an idea of what is happening instead of blaming, I think. Looking at what I say, do and how I relate to others helps me to see what 
happens and can help me to act in a conscious way, perhaps not always in a different or 'right' way.

The theory and the reflection protocols seem to have enabled participants' reflection in ways relevant to their professional practice and its development. However, through participants' meta-reflections, it also became evident that there were participants who struggled with this structure and/or found its underpinning theory difficult to grasp:

The first time the concepts of sayings, doings and relatings were presented to me, I felt confused, if not doubtful. How would I be able to step outside myself and zoom in on what I say, think, do and what I relate to? Well, that's something that just happens. ... The iterative writing within the reflection protocol before going to residential seminars initially felt like rather stressful exercises. This I have re-evaluated from the moment I started writing. To reflect on what has been said and done. Likewise, how I relate to different events and the importance of relationships around them. Arrangements were not something I put much reflection time around earlier but now it is always in the back of the head. Now I carry this in everyday life. I have seen myself by stopping before, but above all after, different events.

Hence, the protocols may have been limiting for some of the participants, at least initially.

When it comes to understanding the participants' relation to and engagement with literature, and in particular their tendency to do so in a way that is rule-following rather than exploratory or critically reflective in the wider academic sense, some answers may be found in the construction of the course, as a form of professional education and an advanced-level academic programme, and in the various policy documents regulating and thus shaping its practices. As mentioned earlier, objectives related to critical reflection are found in the state-provided national Goal Document (Skolverket 2015), and in the Swedish Higher Education Act (1992) and the Higher Education Ordinance (1993), but with varying focus and scope. In the former, critical reflection is mentioned several times but only in relation to participants' own practice; whereas in the later couple of documents, the concept of critical reflection is treated as a general academic skill, which makes its scope wider and implications more extensive. These differences between the documents have previously been discussed by Andreas Bergh and Eva Forsberg (2016), 
who describe education as an academic boundary object (Bowker and Star 1999: 297), constructed to serve several needs and fulfil various purposes. Given that the programme in which the course is offered is a state-regulated and commissioned programme, The National Educational Agency's influence on the education is strong. In this case it is likely to have been, if not a limiting arrangement, at least an influential one.

Some answers might also be found in our (the university educators') communication with the participants, for instance, in written and verbal instructions, particularly those directly related to individual and collective reflection. When revisited and viewed against the backdrop of the findings presented above, it becomes clear that practice was the main focus. Participants were asked to 'discuss (i.e. critically reflect on and problematise) the documented practice' and to 'use concepts, models and reasoning offered by the literature', but when it comes to assessing the value and relevance of these concepts, models and reasoning, very little guidance was offered.

Another arrangement which probably had an impact on these practices is the construction of reflection as assessment. It is reasonable to think that participants produced writings that met the evaluation criteria, or rather, what they believed to be expected from them as participants in this particular course and programme. Perhaps participants thought they were expected to revise their own practice in relation to the knowledge they encountered in course literature, and in lectures given throughout the course, without questioning it.

\section{Conclusion}

As shown above, participants used the theory of practice architecture as a resource when developing and communicating knowledge about their own professional practice. In this sense, the course has become more 'theoretical' since the 'reflective space' was created. At the same time, it has become more 'practical', since participants' practice was placed at the very heart of their learning. In this sense, the educational 'gap' between theory and practice seemed to have narrowed as a result of this work.

In order to further develop this reflective space in higher education, and with respect to the enabling and constraining arrangements considered, it seems necessary to revise some of the arrangements. First, some of the instructions provided to the participants should perhaps be changed, so that a greater emphasis is placed on participants' own inquiry, that is, questions, 
aspirations and problem-solving attempts, as well as attempts to critically reflect on literature. Second, communication with participants throughout their work with the self-studies can be further developed, so that more attention is paid to the difficulties, problems and dilemmas participants are facing as leaders; the ambiguous nature of practice is acknowledged; and participants are encouraged to be curious and questioning, not merely towards their own practice but also towards scientifically constructed, institutionalised images of leadership they are encountered within literature and lectures. Third, other ways of constructing assessment, with greater emphasis placed on learning (as a result of reflection and change) rather than on change (as a result of reflection), may be considered.

In conclusion, the findings highlighted and considered in this article have provided a basis for furthering the 'reflective space' as a means to enhance the quality of learning in higher education.

\section{Acknowledgements}

The author would like to acknowledge the colleagues at the former Centre for Educational Management at Uppsala University involved in the work referred to in this article, and in particular Lena Wiman and Torbjörn Hortlund, for their part in the inquiry drawn upon. I would also like to thank Mikael Magnusson for administrative support, and Elisabet Nihlfors, Anette Forssten Seiser, Karin Thörne and Per Helgesson for reading and commenting on previous versions of the article.

Katina Thelin is a Senior Lecturer at the Department of Education, Uppsala University, Sweden. She conducts research in educational leadership and school development and has a particular interest in interactive research and leadership as a practice. In previous work she has investigated variation in ways of seeing different aspects of educational praxis, and possibilities of developing common ways of seeing as a basis for school development.

Email: katina.thelin@edu.uu.se 


\section{Katina Thelin}

\section{Note}

1. Since the inquiry did not involve any physical intervention on the individuals, or methods used to physically or psychologically affect the participants (who had all completed their studies at the time), no ethical review was needed.

\section{References}

Argyris, C. and D. A. Schön (1978), Organizational Learning: A Theory of Action Perspective (Reading, MA: Addison-Wesley).

Bergh, A. and E. Forsberg (2016), 'Rektorsutbildningens Janusansikte: Vad ska en rektor kunna?' ['The Janus face of Principal Education: What should a principal do?'], in M. Gustavsson, T. Österman, and E. Hållén (eds), Vad ska en svensk kunna? Utbildningen dilemma - intressenas spel? [What should a Swede be able to do? The education dilemma - the game of interest?] (Göteborg: Daidalos), 40-72.

Boud, D., R. Cressey and R. Docherty (eds) (2006), Productive Reflection at Work (New York: Routledge).

Boud, D., R. Keogh and D. Walker (1985), Reflection: Turning Experience into Learning (London: Kogan Page).

Bowker, G. C. and S. L. Star (1999), Sorting Things Out: Classification and its Consequences (Cambridge, MA: The MIT Press).

Dewey, J. (1933), How We Think: A Restatement of the Relation of Reflective Thinking to the Educative Process (Boston: Heath \& Co).

Darling-Hammond, L. (2006), Powerful Teacher Education (San Francisco, CA: Jossey-Bass).

Ellström, P. (2006), 'Two logics of learning', in E. Antonacopoulou, P. Jarvis, V. Andersen, B. Elkjaer, and S. Høyrup (eds), Learning, Working and Living: Mapping the Terrain of Working Life (London: Palgrave Macmillan), 33-49.

Freire, P. [1970] (1972), Pedagogy of the Oppressed (Harmondsworth, UK: Penguin).

The Higher Education Ordinance (1993:100) (Stockholm: Ministry of Education and Research).

Holmes, C. A. (2002), 'Academics and practitioners: Nurses as intellectuals', Nursing Inquiry 9, no. 2: 73-83. https://doi-org.ezproxy.its.uu.se/10.1046/j.1440-1800.2002.00137.

Kemmis, S. (2009), 'Action research as a practice-based practice', Educational Action Research 17, no. 3: 463-474. https://doi.org/10.1080/09650790903093284.

Kemmis, S., J. Wilkinson, C. Edwards-Groves, I. Hardy, P. Grootenboer and L. Bristol (2014), 'Praxis, practice and practice architectures', in S. Kemmis (eds), Changing Practices, Changing Education (Singapore: Springer), 25-41.

Kolb, D. A. (1984), Experiential Learning (Englewood Cliffs, NJ: Prentice Hall). 
Levy, A. (1986), 'Second-order planned change: Definition and conceptualization', Organisational Dynamics 15, no. 1: 5-23. http://doi:10.1016/0090-2616(86)90022-7.

Loughran, J., M. L. Hamilton and V. Kubler LaBoskey (eds) (2004), International Handbook on Self-Study of Teaching and Teacher Education Practices (Dordrecht: Kluwer).

Mihailova, P. (2014), “'A place where open minds meet”: The constraints of alignment and the effects of compulsory teacher training on teaching and learning in higher education', Learning and Teaching: The International Journal of Higher Education in the Social Sciences 7, no. 3: 14-45. http://doi:10.3167/latiss.2014.070302.

Roth, R. (1989), 'Preparing the reflective practitioner: Transforming the apprentice through the dialectic', Journal of Teacher Education 40, no. 2: 31-35. https://doi.org/ $10.1177 / 002248718904000206$.

Russell, T., and J. Loughran (2010), 'A multi-national collection of teacher educators' self-studies of practice', Studying Teacher Education 6, no. 2: 113-114. http://doi.org/ 10.1080/17425964.2010.495884.

Rönnerman, K., C. Edwards-Groves, and P. Grootenboer (2015), 'Opening up communicative spaces for discussion "quality practices" in early childhood education through middle leadership', Nordic Journal of Studies in Educational Policy 1, no. 3: 67-76. http://doi.org/10.3402/nstep.v1.30098.

Rönnerman, K. and S. Kemmis (2016), 'Stirring doctoral candidates into academic practices: A doctoral course and its practice architectures', Education Inquiry 7, no. 2: 93-114. http://doi.org/10.3402/edui.v7.27558.

Schön, D. A. (1983), The Reflective Practitioner (New York: Basic Books).

Skolverket (2015), The National School Leadership Training Programme: Goal Document 2015-2021 (Stockholm: Fritzes).

The Swedish Higher Education Act (1992:1434) (Stockholm: Ministry of Education and Research).

Zuber-Skerritt, O. [1992] (1997), Professional Development in Higher Education: A Theoretical Framework for Action Research (New York: Routledge). 